\title{
RESPONSE OF THE POLYCR YSTALLINE GOLD/ALKALINE SOLUTION INTERFACE TO COMPLEX POTENTIODYNAMIC PERTURBATIONS WITHIN THE POTENTIAL RANGE OF THE THERMODYNAMIC STABILITY OF WATER
}

\author{
R. Cornova O., M. E. Martins and A. J. Arvía \\ Instituto de Investigaciones Fisicoquimicas Teóricas y Aplicadus, División \\ Electroquimica, Sucursal 4, Casilla de Correo 16, 1900 La Plata, Argentina
}

(Receiped 27 June 1979)

\begin{abstract}
The potentiodynamic characteristics of Au/alkaline solution interfaces within the potential range of the thermodynamic stability of water, under different complex potential perturbation conditions are described. The composite $E / I$ contours are interpreted in terms of a reversible initial process involving $\mathrm{OH}$ electrosorption, followed by the formation of $\mathrm{Au}$ (III) surface species when the Au/Au(III) equilibritum potential is reached. The latter process clearly involves the simullaneous participation of ageing effects during the course of the reaction. The results correlate with optical data reported in the literature.
\end{abstract}

\section{INTRODUCTION}

Most of the electrochemical data related to gold electrodes, particularly concertining the oxygen electrosorption and electrodesorption processes refer to acid aqueous electrolytes $[1,2]$. Contrarily these teactions appear to have been less studied in alkaline aqueous electrolytes than in acid electrolytes[3-9]. The potentiodynamic $E / I$ displays in the potential range assigned to the water thermodynamic stability exhibit a relatively large number of anodic and cathodic current peaks and shoulders[10-11]. The characteristics of the cathodic current peaks are sensitive to the type of perturbation applied to the interface. This fact is due at least in part to the ageing of the species anodically formed. The ageing of the electrochemical interfaces can be promoted by different types of potential perturbations [12-14]. Thus, open circuit, potentiostatic and potentiodynamic induced ageing effects can be distinguished [14]. The information derived from the ageing effects reveals interesting details of the electrochemical formation of layers on different electrodes.

It has been recently demonstrated $[15,16]$ that the potentiodynamic $E / I$ profiles related to the electroreduction of oxygen-containing layers, either within the order of a monolayer thickness or thin layers, can be drastically changed when a repetitive triangular potential sweep confined to a certain potential range is applied for a definite length of time. Consequently, the electroreduction current peak potential shifts in the negative potential direction. This is expected for a reactant which, owing to the intermediate perturbation, became more stable than that involved in the conventional triangular potential sweep without the intermediate perturbation. This effect known as the potentiodynamic ageing of the film, has already been described for various electrochemical reactions [16-18] including that of the oxygen-containing monolayer on gold in different acid electrolytes[15].
The present paper also includes the electrochemical response of the gold/alkaline interface to triangularly modulated triangular potential sweeps $[19,20]$. The latter perturbation technique renders straightforward information on the degree of reversibility of possible conjugate redox couples accurring in the course of the reaction including, under certain circumstances, redox couples involving intermediate species.

\section{EXPERIMENTAL}

The electrolysis cell is the same as that already described in previous publications[21,22]. Specpure polycrystalline gold wires of $0.38 \mathrm{~cm}^{2}$ apparent area working electrodes were used. The electrode surface was firstly mirror polished with the purest 300 mesh alumina powder, then the electrode was potential cycled in the alkaline solution to attain the conventional $E / I$ display under repetitive triangular potential sweeps covering the potential range of the water thermodynamic stability [23]. Finally, the $E / I$ displays run with each one of the different potential/time programmes were recorded.

The counterelectrode was also made of pure gold. A $\mathrm{Hg} / \mathrm{HgO}$ reference electrode was used although the electrode potentials given in the text are referred to the reversible hydrogen electrode (rhe) at the solution $\mathrm{pH}$. The following electrolyte solutions (ionic strength $\mathrm{ca}$ 1.3) were employed: $1 \mathrm{M} \mathrm{NaOH}+0.1 \mathrm{M} \mathrm{Na}_{2} \mathrm{SO}_{4}$; $0.1 \mathrm{M} \mathrm{NaOH}+0.4 \mathrm{M} \mathrm{Na}_{2} \mathrm{SO}_{4} ; 0.01 \mathrm{M} \mathrm{NaOH}+$ $0.43 \mathrm{M} \mathrm{Na}_{2} \mathrm{SO}_{4}$. These solutions were made from $\mathrm{AR}$ chemicals and triply distilled water. The electrolytic solutions were continuously kepl under purified nitrogen. Extreme precautions were taken during the experimental work to avoid impurities from the laboratory atmosphere. Taps and ground joints were lubricated with the same electrolyte solution and the gas tubing to be used under a continuous positive pressure was made in part with thick wall PTFE and in part with glass. 


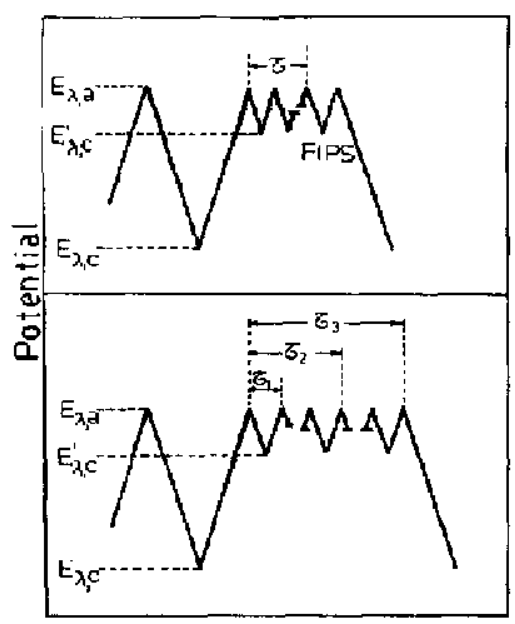

Time

rig. 1. Perturbations programmes. FIPS denules the final intermediate perturbation scan.

Water purity was systematically tested through the characteristics of the voltammogram of the $\mathrm{Pt} / 1 \mathrm{M}$ $\mathrm{H}_{2} \mathrm{SO}_{4}$ interface in the region of hydrogen adatoms using platinum electrodes[24]. The purity criterion was to keep the hydrogen adatom electrooxidation multiple peaks unaltered during the repetitive triangular potential sweeps at $0.05 \mathrm{~V} / \mathrm{s}$ for $10 \mathrm{~min}$ in the cathodic switching potential, $E_{\lambda, c}=0 \mathrm{~V}$, to the anodic switching potential, $E_{3, a}=1.5 \mathrm{~V}$, range.

Experiments were made at $25^{\circ} \mathrm{C}$. The gold/alkaline interfaces were perturbed by the use of the appropriate conventional electronic circuitry including a careful ohmic drop compensation in the following ways. Firstly, a repetitive triangular potential sweep was run between $0.15 \mathrm{~V} \leqslant E_{\lambda, c} \leqslant 0.30 \mathrm{~V}$ and $0.8 \mathrm{~V} \leqslant E_{\lambda, c} \leqslant$ $1.55 \mathrm{~V}$, at equal anodic and cathodic potential sweep rate $\left(v_{a}=v_{c}\right)$ to attain a stable $E / I$ profilc. Then, immediately after the interface was perturbed with the intermediate repetitive triangular potential sweep between $E_{\lambda, c}^{\prime}>E_{\lambda, c}$ and $E_{\lambda, a}$ at $v_{a}^{\prime}=v_{c}^{\prime} \quad\left(v^{\prime} \geqslant v\right)$ during the time $\tau$. Finally, after the last intermediate potential sweep (FIPS), a single negative going linear potential sweep was run (Fig. 1). The duration of the intermediate perturbution, $\tau$, was varied.

The triangularly modulated repetitive triangular potential scanning (TMTPS) technique was also independently applied. The following perturbation characteristics were then used: base signal sweep rate $0.1 \mathrm{~V} / \mathrm{s}$ $\leqslant v_{b} \leqslant 2 \mathrm{~V} / \mathrm{s}$; base signal switching potentials $0 \mathrm{~V} \leqslant$ $E_{\lambda, c} \leqslant 0.2 \mathrm{~V}$ and $0.93 \mathrm{~V} \leqslant E_{\lambda, u} \leqslant 1.79 \mathrm{~V} ;$ modulating signal sweep rate $20 \mathrm{~V} / \mathrm{s} \leqslant v_{m} \leqslant 80 \mathrm{~V} / \mathrm{s} ;$ modulating signal amplitude $0.030 \mathrm{~V} \leqslant \Delta E_{m} \leqslant 0.390 \mathrm{~V}$. The complex $E / I$ contours were photographed from a S02A Tektronix oscilloscope screcn.

\section{RESLLTS}

The $E / I$ displays obtained with a triangular potential perturbation in the potential range of the thermodynamic stability of water exhibits a variety of complementary anodic and cathodic current peaks and shoulders $[3,10,11]$. The shoulders become more clearly distinguished at potential sweep rates greater than $10 \mathrm{~V} / \mathrm{s}$. For the sake of simplicity the $E / I$ plane can be divided at the potential $E_{T}$, the $\mathrm{Au} / \mathrm{Au}$ (III) equilibrium potential, so that the potential range below $E_{T}$ is denoted as the non-oxide region and that above $E_{T}$, as the oxide region[11].

As seen in Figs. 2 and 3 there is a noticeably different behaviour of the electrochemical system whether it covers the non-oxide or the oxide region. In the former case (Fig. 2) for the experiment run at $0.1 \mathrm{~V} / \mathrm{s}$ between $E_{\lambda, c}=0.03 \mathrm{~V}$ and $E_{\lambda, \mathrm{a}}=0.96 \mathrm{~V}$ just before perturbing the electrochemical interface with the intermediate triangular potential sweeps, the $E / I$ displays exhibit flat anodic and cathodic current envelopes and $Q_{c}$, the total cathodic charge, is slightly greater than $Q_{a}$, the total anodic sharge. During the intermediate triangular potential perturbations, the $Q_{\alpha} / Q_{a}$ ratio of each potentiodynamic cycle is always slightly larger than one. This is also the case for the following negative going potential sweep from $E_{\lambda, a}$ to $E_{\lambda, c}$. For the latter, the anodic $E / I$ profile is slightly modified while the cathodic one is more extensively changed as the charge tends to accumulate on the negative potential side.

The changes produced by the intermediate fast potential perturbation in the non-oxide region are relatively less than those found in the oxide region (Fig. 3). The changes produced in the negative potential going $E / I$ profile when $E_{\lambda, a}$ extends into the oxide region where the $\mathrm{Au}(\mathrm{OH})_{3}$ species predorninates[25], depend considerably on $E_{j, t^{\prime}}^{\prime}$, the cathodic switching potential of the fast triangular potential perturbation. Thus, when the potential difference $E_{\lambda, a}-E_{\lambda, c}^{\prime}$ involves the removal and reforming of $c a 30$ per cent of either the anodic or the cathodic charge, a net accumulation of cathodic charge is observed which is

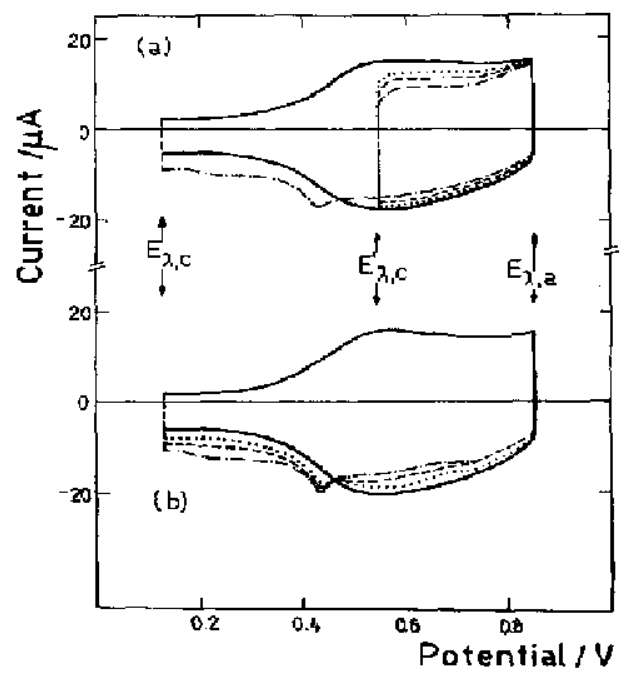

Fig. 2. Potentiodynamic ageing in the non-oxide region. (a) (- - initial stable display at $0.1 \mathrm{~V} / \mathrm{s}$. EiI displays after $\tau_{1}=3 \mathrm{~s}(\ldots \ldots), \tau_{2}=120 \mathrm{~s}(---)$ and $\tau_{3}=300 \mathrm{~s}$ of intermediate perturbation at $0.1 \mathrm{~V} / \mathrm{s}$. The latter covers the $E_{1, \text { a }}$ to $E_{\lambda, c}$ potential range. (b) (- ${ }^{-}$) initial stable display at $0.1 \mathrm{~V} / \mathrm{s}$. $E / I$ displays recorded at $0.1 \mathrm{~V} / \mathrm{s},(\cdots \cdots) \tau_{1}=120 \mathrm{~s},(--)$ $\tau_{2}=300 \mathrm{~s}$ and $(--\cdot--) \tau_{3}=600 \mathrm{~s}$ of the intermediate per. turbation at $1 \mathrm{~V} / \mathrm{s}$. 


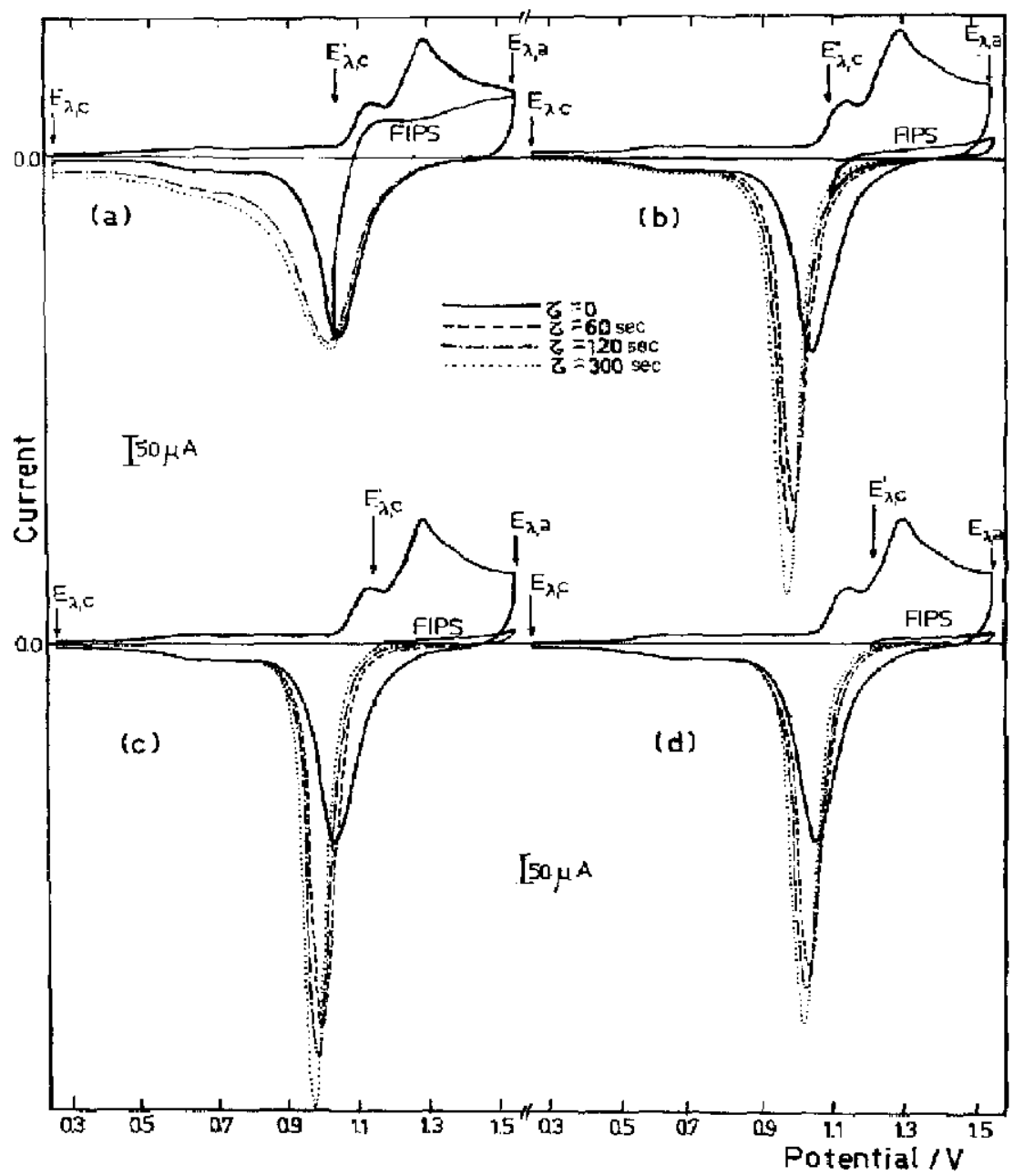

Fig. 3. Potentiodynamic ageing in the oxide region. The intermediate potential perturbation are scanned at $1 \mathrm{~V} / \mathrm{s}$. FIPS are recorded at $0.1 \mathrm{~V} / \mathrm{s}$.

mostly distributed towards the negative potential side of the $E / /$ display overlapping to a large extent with the charge corresponding to the non-oxide region. Then, the height of the main cathodic current peak not only slightly increases but its shape becomes broader than that of the conventional stabilized cathodic current peak [11]. Under these circumstances the electrochemical interface appears relatively active during the intermediate fast perturbation. However, the situation changes according to the $E_{\lambda_{1} \varepsilon}^{\prime}$ values. Thus, as $E_{\lambda, c}^{\prime}$ is fixed at more positive values, the charge increase during the negative going excursion is considerably reduced. The shape of the cathodic current peak is very symmetric and thin and the cathodic current peak potential is located at a potential more negative than that of the current peak obtained through a conventional triangular potential scan[11]. The charge obtaining during the fast perturbation decreases as the number of successive cycles increases.

The preceding description also extends to more positive $E_{\lambda,}^{\prime}$ values, but the largest effect apparently occurs when $E_{\lambda, c}^{\prime}$ coincides with the potential of the first anodic current peak located in the oxide region $[4,11]$. Nevertheless, as $E_{\lambda, c}^{\prime}$ becomcs more positive, namely $E_{\lambda, a}-E_{\lambda,}^{\prime}$ decreases, the electrochemical in terface tends to passivate. Furthermore, the influence of the potentiodynamic ageing in the oxide region on the E/I display in the non-oxide region is considerably diminished as $E_{\lambda, c}^{\prime}$ is more positive. The effect of the potentiodynamic ageing is more noticeable as the time of the fast potential perturbation increases.

In conclusion, the effects produced by the potentiodynamic ageing of the gold/alkaline solution interface can be summarized as follows.

(i) An increase of the cathodic charge in both regions of the E/I display.

(ii) A definite change of the cathodic $E / I$ profile which depends on the duration of the intermediate perturbation.

(iii) A shift of the negative potential going $E / I$ profile towards more negative potentials as should be expected for the appearance of more stable species than those produced under conventional perturbations. 


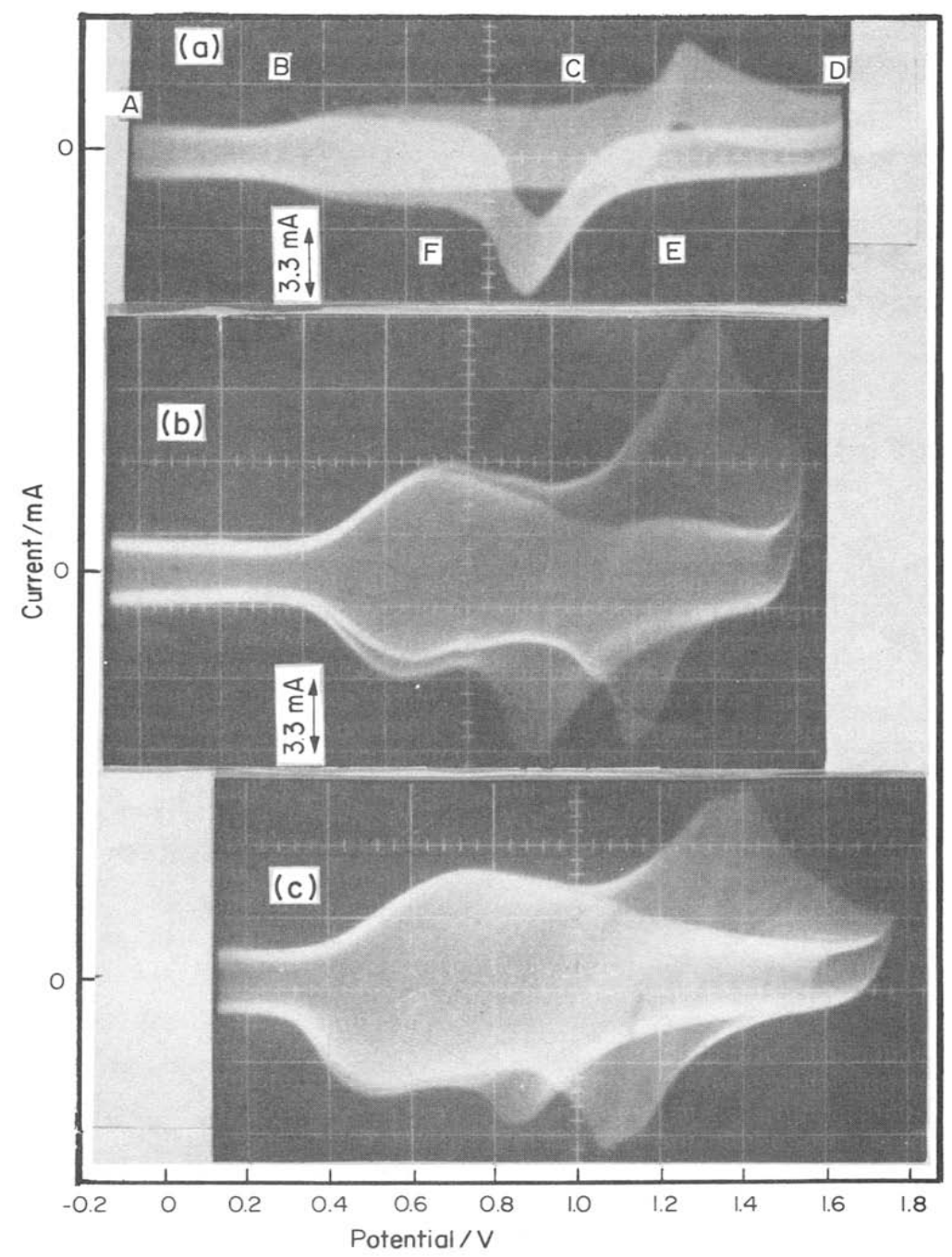

Fig. 4. Triangulary modulated triangular putential sweep $E_{i} I$ displays. $1 \mathrm{M} \mathrm{NaOH}+0.1 \mathrm{M} \mathrm{Na} \mathrm{SO}_{4}, 25^{\circ} \mathrm{C}$. (a) $E_{\lambda, c}=-0.08 \mathrm{~V} ; E_{\lambda, a}=1.64 \mathrm{~V} ; v_{b}=1 \mathrm{~V} / \mathrm{s} ; v_{m}=20 \mathrm{~V} / \mathrm{s} ; \Delta E_{m}=0.030 \mathrm{~V}$. (b) $E_{\lambda, c}=-0.13 \mathrm{~V} ; E_{\lambda, a}=$ $1.56 \mathrm{~V} ; v_{\mathrm{b}}=1 \mathrm{~V} / \mathrm{s} ; v_{\mathrm{m}}=20 \mathrm{~V} / \mathrm{s} ; \Delta E_{\mathrm{m}}=0.120 \mathrm{~V}$. (c) $E_{\lambda, \mathrm{c}}=0.14 \mathrm{~V} ; E_{\lambda, \mathrm{s}}=1.78 \mathrm{~V} ; v_{\mathrm{b}}=1 \mathrm{~V} / \mathrm{s} ; t_{\mathrm{m}}=60 \mathrm{~V} / \mathrm{s} ;$ $\Delta E_{m}=0.240 \mathrm{~V}$.

Additional information about the gold/alkaline solution interfaces, particularly that conccrning the number of anodic and cathodic current peaks as well as their kinetic responses can be derived through the TMTPS experiments. The corresponding $E / /$ displays obtained with a small modulating signal amplitude $\left(\Delta E_{m}=0.03\right.$ V) (Fig. 4) exhibits the following features. During the positive going potential excursion in the potential range AB (Fig, 4a) only the periodic charging and discharging of the double layer is observed. In the potential range BC there is a reversible faradaic contribution together with the dl charging and discharging but the $E / I$ display cxhibits no particular fine structure. Finally, in the potential range $C E$, a rather sluggish faradaic process is involved. During the reverse scan in the DE region the di charging and discharging is predominantly observed. With in the EF potential range a slow faradaic process is noticed and the remaining portion of the negative potential going excursion approaches the shape of the $E / I$ contour already described for the positive going potential excursion within the same potential range.

Further details are observed when modulating signal amplitudes greater than $0.1 \mathrm{~V}$ are employed. Thus, for $\Delta t_{m}=0.120 \mathrm{~V}$ at $v_{m}=20 \mathrm{~V} / \mathrm{s}$ (Fig. 4b) the positive going potential excursion confirms all the anodic current peaks and shoulders already described[11]. However the difference between the potentials of current peaks $I_{a}$ and $I_{c}$ is larger than that found at lower $\Delta E_{m}$ values (Fig. 4a). The positive going potential excursion (Fig. 4b) shows two anodic shoulders preceding current peak $V_{a}$ together with their complementary cathodic currents, namely a cathodic shoulder at $1.07 \mathrm{~V}$, a cathodic current peak at $1.13 \mathrm{~V}$ and another cathodic shoulder at $1.19 \mathrm{~V}$. Then, during the positive going potential excursion the $E / I$ display 
in the $0.9 \mathrm{~V}-1.6 \mathrm{~V}$ range exhibits reasonable reversible electrochemical behaviour. On the other hand, the successive negative going potential excursion in the $1.6 \mathrm{~V}-1.2 \mathrm{~V}$ range displays only a small faradaic contribution. The main ca thodic current peak appears at $0.89 \mathrm{~V}$ and at potentials lower than $0.7 \mathrm{~V}$ the $E / I$ contour approaches the characteristics already described for the preceding positive going potential excursion. The irreversibility of the overall electrochemical process is more noticeable when the potential is swept from $1.6 \mathrm{~V}$ downwards, although it is likely that under these circumstances the cathodic envelope depicted during the negative going potential excursion is to some extent influenced by traces of molecular oxygen produced at the highest $E_{\lambda, \alpha}$ values.

When the froquency of the modulating signal increases (Fig. $4 c$ ) the anodic current peak potentials shift slightly towards more positive values while the cathodic current peak potentials change to the reverse direction. In general, the distribution of the current peak multiplicity depends in part on $v_{m}$. The amplitude of the modulating signal has an influence on the definition of the overall $E / I$ response.

The results obtained from the TMTPS displays confirm the number and location of current peaks previously described through the triangular potential sweep $E / I$ displays either in the absence of any ageing[11] or with potentiodynamic ageing covering different potential ranges. Furthermore, the TMTPS experiments give a more clear understanding about the reversibility of the initial processes related to the electroformation of the oxygen-containing film and the increasing irreversibility of the electrochemical reaction as the potential sweep moves towards the positive potential side. However, the greatest irreversibility is observed in the first half portion of the TMTPS envelope when the potential excursion reverscs towards the negative potential side.

\section{DISCUSSIGN}

The potentiodynamic $E / I$ profiles for the formation and reduction of surface oxide films on gold in alkaline electrolytes exhibit a number of similar features with those studied more in detail in acid electrolytes $[21,22$, 26-28]. The similarities may be both of fundamental and general significance in explaining the early stages of the metal electrooxidation, the stability of the different species formed in the course of the film forming reaction and, eventually, the particular influence of anions on the processes generally described under the heading, ageing effects.

It is already well established that the potentiodynamic $E / I$ profile of the gold/alkaline solution interfaces exhibits an appreciable faradaic current contribution in the $0.45 \mathrm{~V}-c a 1.0 \mathrm{~V}$, that is in the non-oxide region, where the gold/water solvent interface is stable in terms of the thermodynamics derived from the bulk properties of gold and water. The processes occurring there, at the positive side of the potential of zero charge of the metal in these solutions[6], should be ascribed to the same initial stage which has been observed in acid electrolytes $[21,22,27,28]$, namely the reversible formation of $\mathrm{OH}$-electrosorbed species. In this case, however, the reaction should be put forward in terms of $\mathrm{OH}^{-}$species instead of water molecules as in the acid electrolyte[29]. Although the experimental results are usually less distinctive than simple models, the kinetics of the electrosorption reaction of either charged or neutral substances on a metal surface can be described in terms of partial charge transfer reactions $[30-33]$. Then, the reaction in the non-oxide region can be formally presented according to :

$$
\{x \mathrm{Au}\}+y \mathrm{OH}^{-}=\left\{\left[\mathrm{Au} u_{x}\right][\mathrm{OH}]_{y}\right\}^{z-}+(y \cdots z) \epsilon^{\prime}
$$

where $x$ refers to the number of available gold surface sites and $x \geqslant y$. When $x=y$ a monolayer of $\mathrm{OH}$ species are formed. According to (1) the electrosorbed species may be partially charged and eventually when $z=0$, the maximal monolayer charge corresponding to the $\mathrm{OH}$ species is formed. Therefore, (1) may involve a partial charge transfer electrosorption of $\mathrm{OH}^{-}$ species. The fact that the overall charge taking part during the process occurring in the potential range of the "non-oxide" region is, in principle, smaller than that expected for the OH monolayer, may be retated either to the fact that surface saturation is achieved for $y$-values smaller than $x$ or, to the fact that although $x=y$, the value of $z$ is larger than 0 . The monolayer charge is arbitrarily defined by comparison with the hydrogen adatom monolayer on polycrystalline platinum [34] taking into account that the roughness factor of polycrystalline gold is $1.3[37-39]$. The latter value, however, can be larger than 3 for etched gold electrode[46]. At any rate, the absence of any ageing process within the non-oxide potential region and the fast response under the TMTPS perturbation indicate that (1) has to be considered as a fast electrode process. Spectroscopy reflectance [4] and ellipsometric[7-9, 41] data support the existence of surface species in the non-oxide region.

Finally, in the non-oxide region a third relatively minor current contribution is observed as a very small cathodic current peak at $0.53 \mathrm{~V}$ during the cathodic excursion in the $E / I$ displays resulting immediately after the intermediate perturbation, but at present no explanation for this small charge can be advanced.

The main faradaic process represented by (1), as revealed through the TMTPS runs is, however, a composite one, as in the non-oxide region at least two apparently successive faradaic processes are distinguished. These results confirm the complex $E / I$ displays previously obtained from fast potentiodynamic $E / I$ displays run with a progressive increase of the anodic switching potential $\left(E_{\lambda, a}\right)[11]$.

The charge estimated for each one of the faradaic contributions of the $E / I$ profile in the non-oxide region is about the same. Therefore, if one assumes that the overall processes occurring in the non-oxide region yields an $O H$ monolayer when $z=0$ in (1) and $x=y$, it is possible to explain the two conjugate current peaks through the following successive reactions taking place along the positive potential going excursion

$$
\begin{aligned}
\{x \mathrm{Au}\}+ & x \mathrm{OH}- \\
& =\left\{\left[\mathrm{Au} u_{x}\right][\mathrm{OH}]_{x}\right\}^{(x / 2)-}+(x / 2) e
\end{aligned}
$$

and

$$
\begin{aligned}
& \left\{\left[\mathrm{Au} u_{x}\right][\mathrm{OH}]_{x}\right\}^{(x / 2)-} \\
& =\left\{\left[\mathrm{Au} u_{x}\right][\mathrm{OH}]_{x}\right\}+(x / 2) e
\end{aligned}
$$

where the parentheses denote the surface species which 
are formed during the two successive partial transfer processes. The stability of each species can be measured through the corresponding current peak potential. Both (1a) and (1b) behave as reversible electrochemical processes. However, these reactions must be considered only as limiting processes since, as described further on, the $z=0$ condition is apparently attained when the potential exceeds $E_{T}$.

When $E_{\lambda . a}$ is increased beyond $1.0 \mathrm{~V}$ a gradual change of the $E / I$ display run towards the negative going potential direction is noticed. As the distribution and number of the different metal-oxygen species formed on the metal can be deduced from the shape of the negative potential going $E / I$ contour (Fig. 3), one concludes that the largest number of species is formed when the potentiodynamic ageing involves a charge which is slightly larger than one half the overall charge obtaining in the whole potentiodynamic $E / I$ profilc run between $E_{\lambda, c}$ and $E_{\lambda, q-}$ Under these circumstances the overall electroreduction $E / I$ profile, and the main electroreduction current peak are shifted towards the negative potential side. However, the overall cathodic charge recorded immediately after the intermediate perturbation becomes larger than that found in the initial triangular potential sweep $E / I$ display. This effect diminishes noticeably when $E_{\lambda . c}^{r}$ moves towards more positive potential, so that the cathodic charge recorded before and after the intermediate triangular potential perturbations become almost alike. This suggests that the more drastic effect promoted by the intermediate perturbation when $E_{j, c}^{4}$ is more negative can be assigned to a possible penetration of oxygen beyond the first atomic layer of gold. In this way more strongly bound oxygen-containing species in the metal can be produced, which are more difficult for electroreducing. A similar type of surface rearrangement has been recently discussed for the case of platinum/acid electrolytes interfaces under the same type of perturbation conditions [16].

These results give further support to the idea that the ageing process, especially that related to place exchange reactions at the metal surface should be ascribed mainly to the species produced after the $\mathrm{OH}$ electrosorption process, that is, to metal-oxygen species. The latter species through these processes are able to attain more stable configurations.

The oxide region involves the occurrence of three different electrooxidation processes which should start from the electrosorbed $\mathrm{OH}$ species. These reactions can be formally written as follows:

$$
\begin{gathered}
\left\{\left[\mathrm{Au}_{x}\right][\mathrm{OH}]_{y}\right\}^{z-}+y^{\prime} \mathrm{OH}^{-} \\
=\left\{\left[\mathrm{Au} u_{x}\right][\mathrm{OH}]_{x}\right\}+\left(z+y^{\prime}\right) e \\
\left\{\left[\mathrm{Au}_{x}\right][\mathrm{OH}]_{x}\right\}+y \mathrm{OH} \mathbf{H}^{-} \\
=\left\{\left[\mathrm{Au} u_{x}\right][\mathrm{OH}]_{2 x}\right\}+y e \\
\left\{\left[\mathrm{Au}_{\mathbf{x}}\right][\mathrm{OH}]_{2 x}\right\}+y \mathrm{OH}{ }^{-} \\
=\left\{\left[\mathrm{Au} \mathrm{u}_{\mathbf{x}}\right][\mathrm{OH}]_{3 x}\right\}+y e
\end{gathered}
$$

where $y+y^{t}=x$.

Reaction (2) represents the residual discharge of the $\mathrm{OH}$ species and it is assigned to the reversible conjugate couple which is observed in ca $1.2 \mathrm{~V}$ only during the positive potential excursion TMTPS $E / I$ contour (Fig. 4). The relative charge related to (2) is small and appears as a small shoulder on the negative potential side of the main anodic current peak under the triangular potential sweep $E / I$ display. This reaction is not observed during the negative going potential excursion in the TMTPS runs. Since then no OHcontaining species remain on the electrode surface once the $E_{\lambda, f}$ value has been reached. Reactions (3) and (4) are related to the formation of a surface layer approaching the $\mathrm{Au}(\mathrm{OH})_{3}$ stiochiometry [25] and correspond to processes appreciably much slower than those represented by (1) and (2).

The shift of the main electroreduction current peak due to ageing of the species anodically formed in the uxide potential region indicates that the $\left\{\left[\mathrm{Au}_{*}\right][\mathrm{OH}]_{3 x}\right\}$ species acquires a more stable configuration through chemical reactions which can be expressed as:

$$
\begin{aligned}
& \left\{\left[\mathrm{Au}_{\boldsymbol{x}}\right][\mathrm{OH}]_{3 x}\right\} \\
& \quad=\left\{\left[\mathrm{Au}_{x}\right]\left[\mathrm{O}_{n}\right][\mathrm{OH}]_{(3 x-\mu)}\right\}^{n-}+n \mathbf{H}^{+} .
\end{aligned}
$$

Reaction (5) would involve an oxygen exchange in the film, where the place exchange mechanism is assisted by the $\mathrm{OH}^{-}$ion at the interface. Reaction (5) attempts to represent an average type process related to the ageing effects at the gold/alkaline electrolyte in terface. This leaves open the possibility that different types of aged species can be produced.

Since the anodic reaction yields different species the electroreduction process is also a composite one in wolving different reactants whose contributions during the polentiodynamics excursion depend upon the perturbation programme applied to the electrochemical interface. These reactions can formally be written as:

$$
\begin{aligned}
& \left\{\left[\mathrm{Au}_{x}\right][\mathrm{OH}]_{3 x}\right\}+(2 x) e \\
& =\left\{\left[\mathrm{Au}_{\boldsymbol{x}}\right][\mathrm{OH}]_{x}\right\}+(2 x) \mathrm{OH}^{-} \\
& \left\{\left[\mathrm{Au}_{x}\right]\left[\mathrm{O}_{\mathrm{n}}\right][\mathrm{OH}]_{(3 x-n)}\right\}+n \mathrm{H}_{2} \mathrm{O}+(2 x) e \\
& =\left\{\left[\mathrm{A} \mathbf{u}_{x}\right][\mathrm{OH}]_{x}\right\}+(2 x+n) \mathrm{OH}^{-}
\end{aligned}
$$

and

$$
\left\{\left[\mathrm{Au}_{\boldsymbol{x}}\right][\mathrm{OH}]_{\boldsymbol{x}}\right\}+x e=\{x \mathrm{Au}\}+x \mathrm{OH} \mathrm{H}^{-} .
$$

The largest irreversibility of (7) should involve not only the place exchange mechanism in the film but also the water rearrangement at the electrochemical interface as part of the elementary steps of electrosorption processes[42]. Furthermore, the place exchangemechanism related to the oxide film formation is influenced by the nature and concentration of the anions present in the electrolyte. The usual result is the local stabilizing influence of anions on the agcing effect in the metal surface[43].

The present results correlate with the fact that complex changes of the experimental ellipsometric data for the $\mathrm{Au} / \mathrm{N} \mathrm{KOH}$ interface, specially in the monolayer region, should be cxplained by the formation of surface species whose properties are both potential and time dependent $[7-9]$.

From the slopes of the individual intermediate potentiodynamic fast triangular potential perturbations at each potential the change of resistance of the film can be followed. Thus, when the $E_{\lambda, \mathrm{c}}^{\prime}-E_{\lambda, a}$ potential difierence is located towards more positive potential, the slope of the $E / I$ display progressively 
decreases. This indicates that the electrical resistance increases as the charge of the oxygen containing layer also increases. This correlates with the conclusions reported for the acid electrolyte that the mechanism of growth of the oxygen containing layer changes with increasing overvoltage[39]. The reason for this change is, however, not clear and deserves further investigation, especially in that which concerns the alkaline electrolyte.

Finally, the influence of the increasing concentration of $\mathrm{SO}_{4}^{2-}$ ions is similar to that already reported for the acid electrolyte [43], namely to compete through specific adsorption with other ions and solvent molecules to block the surface. The larger the $\mathrm{SO}_{4}^{2-}$ ion concentration the larger the overvoltage to accomplish similar effects while a poorer resolution of the $E / I$ profile is observed. These effects are, in any case, less noticeable in the alkaline than in the acid electrolytes.

Acknowledgement - INIFTA is sponsored by the Consejo Nacional de Investigaciones Cientificas y Técnicas, the Universidad Nacional de La Plata and the Comisión de Investigaciones Cientificas (Provincia de Buenos Aires). This work was partially sponsored by the Regional Program for the Scientific and Technological Development of the Organization of the American States. R. Córdova Orellana, participates as a visiting Professor of the University of La Plata, under a leave of absence from the Universidad Católica de Valparaiso, Chile.

\section{REFERENCES}

1. G. M. Schmid and M. E. Curley-Fiorino, Encyclopedia of Electrochemistry of the Elements (Edited by A. J. Bard), Vol. IV, Ch 3, p. 87, Dekker, New York (1975).

2. R. Woods, in Advances in Electroanalytical Chemistry (Edited by A. J. Bard), Vol. 9, p. 119 , Dekker, New York (1977).

3. D. E. Icenhower, H. B. Urbach and J. H. Harríson, $J$. electrochem. Soc. 117, 1500 (1970).

4. T. Takamura, K. Takamura, W. Nippe and E. Yeager, $J$. electrochem. Soc. 117, 626 (1970).

5. D. M. MacArthur, $J$. electrochem. Soc. 119, 672 (1972).

6. D. D. Bode, T. N. Anderson and H. Eyring, J. phys. Chem. 71, 792 (1967).

7. Yu. Ya. Vinnikov, V. A. Shepelin and V. I. Veselovskii, Elektrokhtmiya 8, 1229 (1972).

8. Yu. Ya. Vinnikov, V. A. Shepelin and V. I. Veselovskii, Elektrokhimiya 8, 1384 (1972).

9. Yu. Ya. Vinnikov, V. A. Shepelin and V. I. Veselovskii, Elektrokhimiya 10, 650 (1974).

10. J. Gonzales-Yelasco and J. Heitbaum, J. electroanal. Chem. 54, 147 (1974).

11. R. Córdova O., M. E. Martins and A. J. Arvía, $J$. electrachem. Soc. 126, 1172 (1979).

12. M. D. Goldshtein, Ts. 1. Zalkind and V. L. Veselovskii, Elektrokhimiya 8, 606 (1972).
13. A. J. Arvía, An. Quim. (España), 71, 944 (1975).

14. A. J. Arvia, Israel $J$. Chem. (in press).

15. N. R. de Tacconi, J. O. Zerbino, M. E. Folquer and A. J. Arvía J. electroanal. Chem. 85, 213 (1977).

16. M. E. Folquer, J. O. Zerbino, N. R. de Taceoni and A. J. Arvia, J electrochem. Soc. 126, 592 (1979).

17. R. S. Schreblec G., J. R. Vilche and A. J. Arvia, J. appl. Electrochem. 9, 321 (1979).

18. R. Cordova O., M. E. Martins and A. J. Arvía, Electrochin. Actu 24, 469 (1979).

19. B. E. Conway, H. Angerstein-Kozlowska, F. C. Ha, J Klinger, B. MacDougall and S. Gottesfeld, Discuss. Faraday Soc., 56, 210 (1973).

20. N. R. de Tacconi, J. O. Zerbino and A. J. Arvía, J. electroanal. Chem. 79, 287 (1977)

21. C. M. Ferro, A. J. Calandra and A. J. Arvía, J. electroana!. Chem. 59, 239 (1975)

22. C. M. Ferro, A. J. Calandra and A. J. Arvía, d. electroanal. Chem. 65, 963 (1975)

23. M. Pourbaix, Atlas of Electrochemical Equillbria in Aqueous Solutions, Pergamon Press, New York (1966).

24. B. E. Conway, H. Angerstein-Kozlowska, W. B. A. Sharp and E. E. Criddle, Analyt. Chem. 45, 1331 (1973)

25. K. Ogura, S. Harnyama and K. Nagasaki, J.electrochem. Soc. 118,531 (1971).

26. H. Angerstein-Kozlowskn, B. E. Conway and J, Klinger, $J$. electroanal. Chem. 75, 45 (1977).

27. H. Angerstein-Kozlowska, B. E. Conway and J. Klinger, J. electroanal. Chem. 87, 301 (1978).

28. H. Angerstein-Kozlowska, B. E. Conway and J. Klinger, J. electroanal. Chem. 87, 321 (1978).

29. M. H. Miles, J. H. Huang and S. Srinivasan, J. electrochem. Soc. 125, 1931 (1978).

30. J. W. Schultze and F. D. Koppitz, Electrochim, Acta 21 , 327 (1976)

31. G. P. Klein, K.J. Vetter and J. W. Schuluze, Z. phys. Chem NF, 99, 1 (1976).

32. J. W. Schultze, Ber. Bunsenges. Phys. Chem. 74, 705 (1970).

33. J. W, schultze and D. Dickertmann, Ber. Bunsenges. Phys. Chem. 82, 528 (1978).

34. S. Gilman in Electroanalytical Chemistry (Edited by A. J. Bard), Vol. 2, p. 111, Dekker, New York (1967).

35. T. Biegler, D. A. J. Rand and R. Woods, $J$. electroanal. Chem. 29, 269 (1971).

36. A. T. Hubbard, R. M. Ishikawa and J. Katekaru, $f$. electroanal. Chem. 86, 271 (1978).

37. J. W. Schultze and K. J. Vetter, Ber. Bunsenges. Phys. C'kem. 75, 470 (1971).

38. D. Dickertmann, J. W. Schultze and K. J. Vetter, $J$. electroanal. Chem. 55, 429 (1974).

39. M. M. Lohrengel and J. W. Schultze, Electrochim. Acta 21, 957 (1976).

40. T. Dickinson, A, F. Poyey and P. M. A. Sherwood, J chem. Sac, Faraday I, 71, 298 (1975).

41. R. S. Sirohi and M. A. Genshaw, J.electrochem. Soc. 116 , $910(1969)$.

42. J. W. Schultze, Extended Abstracts, 155 th Meeting, Vol 79-1, p. 849, The Electrochemical Society, Boston (1979).

43. R. Lezna, N. R. de Tacconi and A. J. Arvía, J. electrochem. Soc. (in press). 